\title{
Dezembros selvagens: pequeno retrato da Irlanda rural e seus conflitos
}

\author{
Wild decembers: small portrait of rural Ireland and its \\ conflicts
}

\section{Wild decembers: pequeño retrato de irlanda rural y sus conflictos}

\author{
(D) Munike Martins Bonet \\ Universidade Federal do Tocantins (UFT), Palmas, Tocantins, Brasil. \\ E-mail: mony_mb20@yahoo.com.br \\ iD 9 Rejane de Souza Ferreira \\ Universidade Federal do Tocantins (UFT), Palmas, Tocantins, Brasil. \\ E-mail: rejaneferreira@uft.edu.br
}

Resumo: Este artigo problematiza a rigidez da moralidade e do gênero em Dezembros selvagens (2003), de Edna O' Brien, bem como a relação triangular entre os irmãos Joseph e Breege e o irlandês exilado Mick Bugler. Pressupomos que existe um desejo incestuoso da parte de Joseph que se torna ameaçado com a chegada desse exilado, gerando conflitos como disputas de terra e violências diversas. Assim, observamos de que forma os ambientes social e cultural dos personagens se refletem no comportamento deles. A presente análise é também uma forma de contribuir para o processo de desconstrução de estereótipos e para a problematização de conflitos que permaneciam camuflados por aparências pautadas em princípios e valores. Para tanto, nos baseamos em Abrantes (2010), Showalter (2003) e Freud (1990), bem como nas suas releituras por Lacan (1995). Ao final, compreendemos que, por meio do enredo da obra, O’ Brien não só questiona a percepção hegemônica de identidade cultural, como também problematiza as fronteiras entre a terra e a mulher.

Palavras-chave: Irlanda. Família. Mulher. Conflito. Edna O’ Brien 


\begin{abstract}
This article problematizes the rigidity of morality and gender in Wild Decembers (2003), by Edna O 'Brien, as well as the triangular relationship between the brothers Joseph and Breege and the exiled Irishman Mick Bugler. We assume that there is an incestuous desire on the part of Joseph that becomes threatened with the arrival of this exile, generating conflicts such as land disputes and diverse violence. Thus, we observe how the social and cultural environments of the characters are reflected in their behavior. The present anlysis is also a way to contribute to the process of deconstructing stereotypes and problematizing conflicts that remained camouflaged by appearances based on principles and values. For that, we based on Abrantes (2010), Showalter (2003) and Freud (1990), as well as on their readings by Lacan (1995). In the end, we understand that through the plot of the work, $\mathrm{O}$ 'Brien not only questions the hegemonic perception of cultural identity, but also questions the boundaries between the land and the woman.
\end{abstract}

Keywords: Ireland. Family. Woman. Conflict. Edna O' Brien

Resumen: Este artículo analiza la rigidez de la moralidad y el género en Wild Decembers (2003) de Edna O'Brien, así como la relación triangular entre los hermanos Joseph y Breege y el irlandés exiliado Mick Bugler. Suponemos que hay un deseo incestuoso por parte de Joseph que se ve amenazado por la llegada de este exilio, generando conflictos como disputas territoriales y violencia diversa. Así, observamos cómo los entornos sociales y culturales de los personajes se reflejan en su comportamiento. El presente análisis es también uma forma de contribuir al proceso de deconstrucción de estereótipos y a problematizar conflitos que quedaron camuflados por apariencias basadas em princípios y valores. Para ello, nos basamos en Abrantes (2010), Showalter (2003) y Freud (1990), así como en sus lecturas de Lacan (1995). Al final, entendemos que a través de la trama de la obra, $O$ ‘Brien no solo cuestiona la percepción hegemónica de la identidad cultural, sino que también cuestiona los límites entre la tierra y la mujer.

Palabras clave: Irlanda. Familia. Mujer. Conflicto. Edna O' Brien

Submetido em 04 de setembro de 2020.

Aceito em 11 de outubro de 2020.

Publicado em 26 de março de 2021. 
Dezembros selvagens: pequeno retrato da Irlanda rural e seus conflitos Munike Martins Bonet • Rejane de Souza Ferreira

\section{Introdução}

O presente artigo analisa a relação triangular entre os irmãos Joseph e Breege e o irlandês exilado Mick Bugler, que retorna à Irlanda para assumir as terras que herdou. Partimos do pressuposto de que existe um desejo incestuoso da parte de Joseph que se torna ameaçado com a chegada desse exilado, gerando conflitos como disputas de terra e violência física e psicológica. Observamos de que forma os ambientes social e cultural em que os personagens estão inseridos se refletem nas relações familiares e seus conflitos, além de analisar como a autora problematiza a imagem que o irlandês tem de si mesmo, do outro (a partir de Mick Bugler) e da mulher. Esses temas trazidos por O'Brien, assim como outras questões-tabu relacionadas à vida privada das famílias irlandesas, fazem parte de uma cultura de silêncio que paira no país. De acordo com Rejane de Souza Ferreira (2014), esse silêncio é opressor e em muito limita a discussão de certos assuntos e, consequentemente, a busca por soluções. Ainda, no que diz respeito a esse silêncio, Linda Clarke afirma que ele está intrinsecamente associado à própria cultura irlandesa:

A identificação da Irlanda como uma mulher, várias vezes personificada como My Dark Rosaleen (Roisin Duhn), Kathleen Ni Houlihan, Mãe Eire e assim por diante, apresenta uma visão romântica imaginária da Irlanda como mulher, ou seja, Mãe. Nos anos anteriores à independência, essa visão da Mãe Irlanda necessitando de proteção tornou-se uma marca registrada do nacionalismo, mas também exigia a intervenção masculina para estabelecer plenamente seus direitos como Poder Soberano. Alguns comentaristas argumentam que a Irlanda retratada como Mãe foi tão eficaz que está arraigada à ideia de mulher em papeis estereotipados e criou uma estrutura estatal e cultura na Irlanda, em que os homens ocupam o papel político de lutar pelos direitos da Irlanda e como tal em nome das mulheres. [...] 
Dezembros selvagens: pequeno retrato da Irlanda rural e seus conflitos

Munike Martins Bonet • Rejane de Souza Ferreira

Isso define Mãe/mulher como “personificações passivas e silenciosas"1 (CLARKE, 2013, p.1, tradução nossa, grifos nossos).

O romance objeto deste estudo faz parte de uma trilogia publicada pela irlandesa Edna O' Brien nos anos 90: House of Splendid Isolation (1994), Down by the River (1996) e Wild Decembers (1999). Nessa trilogia, a autora aborda três temas importantes: política, sexo e disputa de terra. O último volume, traduzido como Dezembros selvagens (2003), retrata uma comunidade local e questiona a imagem do camponês, persistente como a verdadeira identidade do homem irlandês. Segundo Jennifer Slivka (2013), o que O'Brien subverte está associado aos papéis fixos de moralidade e de gênero das mulheres como preservadoras da raça e de valores como maternidade, tradição e estabilidade.

\section{Moralidade e gênero em dezembros selvagens}

A obra em foco não possui linearidade narrativa e se alterna entre a voz de Breege, de Joseph e de um narrador onisciente, configurando uma multiplicidade de pontos de vista. O ambiente principal da narrativa é o meio rural do condado fictício de Cloontha, Irlanda. Mick Bugler, o exilado, chega da Austrália para reclamar as terras que recebera de herança na referida comunidade rural. Embora filho de irlandeses, constituiu sua identidade em outra realidade, sendo assim não construiu seu Irishness (sentimento de pertencimento irlandês), de modo que sua chegada causa agitação e resistência nos moradores locais.

Seus vizinhos, Breege e Joseph Brennan, são filhos de uma antiga família do lugar. Toda a vida de Joseph, seus hábitos, o modo como conduzia a propriedade e a relação que desenvolveu com a irmã, que

\footnotetext{
$1 \mathrm{Em}$ tradução livre do original: The identification of Ireland as a woman, variously personified as My Dark Rosaleen (Roisin Dubh), Kathleen Ni Houlihan, Mother Eire and so on, presents an imaginary romantic vision of Ireland as a woman, namely Mother. In the years preceding independence, this view of Mother Ireland in need of protection became a hallmark of nationalism but also one requiring male intervention to fully establish her rights as a Sovereign Power. Some commentators have argued that Ireland depicted as Mother has been so effective that it is entrenched in the idea of woman in stereotypical roles and created a state structure and culture in Ireland whereby men occupy the political role of fighting for the rights of Ireland and as such on women's behalf. [...] This defines Mother/woman as "passive and silent embodiments".
} 
Dezembros selvagens: pequeno retrato da Irlanda rural e seus conflitos

Munike Martins Bonet • Rejane de Souza Ferreira

é fortemente subordinada a ele, faziam parte da cultura irlandesa. Após a chegada de Bugler, Joseph se aflige até perder o controle de suas ações. Tudo aquilo que fazia parte de seu plano pessoal estava, até então, livre de quaisquer interferências externas.

Em princípio, enquanto Bugler está se estabelecendo no condado, Joseph se comporta como um bom anfitrião, sente-se importante por todo o conhecimento que possui daquelas terras e chega até mesmo a ensaiar uma amizade com Bugler, por meio de caçadas e cartas que envia para o vizinho, falando-lhe sobre a região. Contudo, ao tomar conhecimento de que Bugler havia realizado um contrato de arrendamento que sempre fora de Joseph, iniciam-se os mal-entendidos. Quando chega até ele a notícia de que sua irmã havia pegado carona no trator de Bugler, Joseph perde a cabeça pela primeira vez e a esbofeteia: "Uma pancada dura como castigo de mestre-escola" (O'BRIEN, 2003, p. 87). Breege se lamenta e percebe que terá de reprimir seus sentimentos. Essa desestabilização de Joseph advinda da chegada de Bugler está associada à oposição que ele representa. De acordo com Slivka: "A presença estrangeira de Bugler perturba os direitos de Joseph à terra em que se baseia a sua identidade e desafia os seus presumíveis 'direitos' sobre a sua irmã como patriarca substituto"2 (2013, p. 117).

Segundo Albetânia de Sousa (2020), quanto mais identificação ocorrer do indivíduo com um determinado grupo, mais se acentuará a diferença em relação a outros grupos e, dentro desse processo de semelhança, um indivíduo se torna conformista mediante um processo de reprodução inconsciente. Na diferença, na oposição, surge a reação à atitude organizada por meio das tensões entre si mesmo e o Outro. De modo que a chegada de Bugler, sua aproximação da família e o encantamento de Breege atuam como um catalizador desse choque que evidencia as diferenças de Joseph em relação ao Outro, levando-o a um processo de resistência constante contra todas as ações do vizinho, considerando-as

2 Em tradução livre do original: Bugler's foreign presence unsettles Joseph's native rights to the land upon which his identity is based and challenges his presumed "rights" over his sister as a surrogate patriarch when Bugler and Breege become lovers. 
Dezembros selvagens: pequeno retrato da Irlanda rural e seus conflitos Munike Martins Bonet • Rejane de Souza Ferreira

como uma afronta pessoal. Para melhor discutir essa questão da identidade cultural, lançamos mão da perspectiva de Stuart Hall:

As culturas nacionais são compostas não apenas de instituições culturais, mas também de símbolos e representações. Uma cultura nacional é um discurso - um modo de construir sentidos que influencia e organiza tanto nossas ações quanto a concepção que temos de nós mesmos. As culturas nacionais, ao produzir sentidos com os quais podemos nos identificar, constroem identidades. Esses sentidos estão contidos nas histórias que são contadas sobre a nação, memórias que conectam seu presente com seu passado e imagens que dela são construídas (2014, p. 50).

De modo que, ao se tornar mais evidente o interesse de sua irmã por este outro, Joseph passa a nutrir uma antipatia incontrolável pelo novo morador da região, a ponto de prender-lhe o cachorro por ir até sua propriedade. Segundo ele, o cachorro corrompia sua cadelinha Goldie "a fazia irrequieta, a chamava para fora à noite" (O'BRIEN, 2003, p. 89). Por conta disso, ele afirmava que o cachorro merecia uma lição, sob as palavras de Breege:

Joseph o põe em um estábulo vazio dentro de um saco, cobrin-
do-o para abafar os rugidos, buracos no saco para impedir que
morresse. À noite ele chorou e Goldie no calor da cozinha cho-
rou de volta [...]. Os gritos de fora foram ficando mais solitários,
mais tenebrosos quando a noite chegou, eles me comiam por
dentro (O'BRIEN, 2003, p. 90).

Notamos que a atitude de Joseph com os cães representa uma forte ameaça a Bugler, uma demonstração de sua insatisfação quanto ao fato de ele se aproximar de Breege. Corroborando os impasses gerados por essa relação triangular, dois conhecidos da família, Caco e Josephine, simulam cartas e um encontro entre Breege e Bugler, que, além de não acontecer, causa duras con- 
Dezembros selvagens: pequeno retrato da Irlanda rural e seus conflitos

Munike Martins Bonet • Rejane de Souza Ferreira

sequências para Breege que, não só descobre que foi vítima de uma armação, como também é encontrada na estrada pelo irmão enfurecido, "ele a viu como nunca vira antes, uma Jezabel ${ }^{3}$, dentro de um vestido colante" (O'BRIEN, 2003, p. 105). O fato de Breege usar um vestido justo insinuou um comportamento provocativo e despertou em Joseph a percepção de que estava perdendo o controle sobre ela e mais, vendo-a como uma mulher, que de alguma forma Ihe pertencia, indo ao encontro de outro homem. Por isso, empurra-a contra a parede da cozinha de casa e a agride novamente, dessa vez, de forma ainda mais violenta:

No fundo dos olhos dele ódio, aquele ódio cego que é o oposto do amor. Ele a esmurrou com ambas as mãos, esmurrou selvagemente [...] Ele riu gargalhada amarga e impiedosa, e a desafiou a admitir que sim, ela teria se atirado nos braços de Mick Bugler, faminta. Seu humor piorou ainda mais porque ela se recusava a responder. Ele a agrediu agora perversamente (O'BRIEN, 2003, p. 107).

Breege sentia-se violada de todas as formas, iludida por uma farsa mesquinha e ferida pelo irmão, que lhe jurara proteção, as lembranças de suas palavras, "ele dizendo a ela que era seu cavaleiro e a defenderia contra tudo" (O'BRIEN, 2003, p. 109). O acesso de raiva de Joseph evidencia duas situações, a primeira delas a da mulher como propriedade do homem, seja o pai, o irmão ou o marido, numa construção social hierarquizada que situa o homem como dominador.

A segunda diz respeito a uma análise mais profunda da relação de Joseph com sua irmã, posto que os sentimentos que nutre por ela podem ser interpretados como incestuosos. Partindo da teoria freudiana do Complexo de Édipo, exposta em Totem e Tabu (1990), o homem escolhe a mãe como primeiro objeto de amor, talvez a

\footnotetext{
3 Em Apocalipse 2, o nome Jezabel é dado a uma profetisa ou a um grupo da igreja em Tiatira que encorajava a idolatria e a imoralidade. Tornou-se símbolo de alguém que promovia falsas crenças e adoração. Os ensinamentos de Jezabel, como a prostituta da Babilônia, levaram os cristãos a se envolverem em idolatria espiritual e fornicação. Foi acusada de prostituição, uma acusação realmente negativa contra a esposa de um rei. O termo provavelmente tinha sentido espiritual, significando alguém que desviou Israel de seu compromisso com Deus (RIBEIRO, 2015).
} 
Dezembros selvagens: pequeno retrato da Irlanda rural e seus conflitos Munike Martins Bonet • Rejane de Souza Ferreira

irmã também, antes de chegar a sua escolha final, "de modo que seu amor é desviado das duas figuras sobre quem sua afeição se centralizava na infância, para um objeto externo modelado sobre elas" (FREUD, 1990, p. 15). Joseph não se casa e nem permite que Breege o faça, consolidando uma relação patológica na qual a irmã assume um papel de esposa.

Além disso, há o fato de os irmãos serem órfãos, situação que pode ser motivadora desse comportamento patológico de Joseph para com Breege. De acordo com a releitura freudiana de Jacques Lacan (1995), a experiência edípica perpassa três tempos, sendo o último deles contemporâneo ao estádio do espelho, o equivalente à interdição do incesto:

\begin{abstract}
É no terceiro momento do complexo de Édipo que acontece a intervenção do pai real, ao demonstrar que possui o falo e que não o cede e não dá, o pai castra a criança, no sentido de estabelecer a impossibilidade relacionada a continuidade da criança se apresentar como falo para a mãe. O sujeito então é livrado da tarefa impossível e angustiante de ser o falo, quando compreende que o pai o possui. Essa operação permite que o sujeito se identifique com o pai. Nessa identificação simbólica, o sujeito abre mão de certa medida de agressividade ligada à primeira identificação imaginária. Nesse sentido, Lacan segue Freud afirmando que o Supereu se forma a partir dessa identificação edípica com o pai (NOCCHI, 2010, p. 37).
\end{abstract}

Visto que esse simbólico representa o campo da lei, a passagem pelo complexo de Édipo tem como efeito estabelecer uma função normativa e normalizadora. Ainda de acordo com as teorizações de Lacan, mesmo tendo completado seu processo, é impossível resolver totalmente o complexo e nenhum sujeito sairá dele totalmente são. Porém, no caso das perversões, há algo de incompleto nessa travessia (NOCCHI, 2010). O incesto se inclui nas perversões advindas dessas possíveis rupturas, que, em se tratan- 
Dezembros selvagens: pequeno retrato da Irlanda rural e seus conflitos

do de Joseph, devido à não interdição do incesto, acabou gerando um processo de substituição da mãe pela irmã e um medo inconsciente de perdê-la novamente. Logo, a mente pervertida de Joseph - sendo assolada pela chegada de Bugler - e um sistema social em que a mulher é naturalmente subjugada se tornam o campo ideal para o desencadeamento da sequência de conflitos ocorridos e das insanidades cometidas por Joseph.

Quanto a Bugler, assim como descreve o advogado de Joseph, apresenta um sintoma conhecido como "a inferioridade de um exilado que retorna... não um filho da terra... um rapaz colonizado..." (O'BRIEN, 2003, p. 122), de alguém que sofreu por estar sempre em um entrelugar. A Austrália não era sua terra, sua mãe o fizera acreditar que a Irlanda o receberia como a um filho que retorna, e lá ele construiria sua vida. Contudo, conforme a própria descrição do advogado, "nós sabemos quem somos. Para um homem como ele, morros distantes parecem verdes. Não haveria lembranças reais de sua infância" (O'BRIEN, 2003, p. 123). Assim, ele segue não assimilado pela comunidade.

Um momento muito simbólico para essa questão do sentimento de não pertencimento se dá quando dois carneiros do rebanho de Bugler, ao serem afastados de sua mãe, se jogam insistentemente contra a cerca, no que pode ser interpretado como uma metáfora de seu próprio desespero por não conseguir se estabelecer na Irlanda da forma como sua mãe profetizava, essa pátria mítica ao mesmo tempo em que é desejada se torna um fardo.

Os moradores locais projetam em Bugler a imagem de um invasor do qual devem se vingar. De acordo com Slivka (2013), ocorre uma associação da imagem de Bugler ao trauma do colonizador, o que se evidencia nas ações dos moradores locais contra ele. Primeiro, as irmãs Rita e Reena tramam um jantar para seduzi-lo e roubar-lhe todo o feno; depois, a usurpação de seu nome na armadilha das cartas de amor, enganando Breege, além da obsessão de Joseph em impedi-lo que faça as melhorias que deseja em suas terras, seja por meios legais ou ilegais. Essas atitudes frustram por completo as expectativas de Bugler, que sequer supunha que sua 
Dezembros selvagens: pequeno retrato da Irlanda rural e seus conflitos Munike Martins Bonet • Rejane de Souza Ferreira

chegada seria capaz de evidenciar tantos pontos de tensão que a comunidade local claramente queria manter inalterados:

Quanto ao presente, nossa maneira de viver está mudando, mas algumas coisas continuam do mesmo jeito. Veja os brejos, os brejos cobertos como são chamados, são lugares sagrados e o repositório de nosso passado. Cavar fundo um brejo coberto é cortar o tempo para desencavar a história. Há camadas e camadas de vegetação viva. A turfa é refúgio para todo tipo de vida selvagem. Fosse você explorá-la encontraria mais pássaros e bichos e insetos do que na Arca de Noé. Ninguém corta turfa agora porque dizem que já não temos verão para deixá-la secar. Preguiça. Ainda assim, de certa maneira estamos preservando nosso passado. Podemos não ser o condado mais rico, mas temos mais lembranças e mistério que todos (O'BRIEN, 2003, p. 38).

Breege, por sua vez, se vê dividida entre as tradições e o amor. Ela não encontra espaço para desenvolver sua própria identidade, pois a ela é imposto um papel social de gênero rigidamente fixado: seu irmão atua como pai e marido substituto, situação que lhe retira a própria voz. Quando os irmãos se encontram com Bugler, e ele os convida para um passeio de trator, é perceptível que o diálogo só existe entre os homens, pois Joseph responde por Breege. Ela também costumava escrever seus desejos com um pouco de farinha de trigo em cima do forno depois de fazer pão, "ela costumava escrever coisas daquele modo, para fazê-las durar" (O'BRIEN, 2003, p. 35), mesmo que ela soubesse que não durariam mais do que alguns minutos, para ela ainda assim significava algum alento.

Após acentuar-se a inimizade entre Joseph e Bugler, os desejos de Breege são ainda mais sobrepujados pelas circunstâncias em que ela vive. Alguns episódios são cruciais para compreender como isso se dá. Por exemplo, há um momento de colisão entre o seu desejo, suas crenças e as imposições culturais limitantes, o encontro com Bugler após a briga judicial estabelecida entre ele e seu irmão. Encontram-se no cemitério, ela sentia-se bem naquele 
Dezembros selvagens: pequeno retrato da Irlanda rural e seus conflitos Munike Martins Bonet • Rejane de Souza Ferreira

lugar, ele até lhe questiona: "Por que você quer seu próprio túmuIo?" (O'BRIEN, 2003, p. 202) quando ouve dela "Um pouco de paz" (O'BRIEN, 2003, p. 202), complementando que a paz lhe faltava, pois sempre havia "alguma coisa". Breege demonstra compreender sua situação, ela tem consciência da realidade que Ihe foi imposta, mas compreende também que debater-se contra ela seria inútil, pois há algo maior que ela não seria capaz de vencer. Esse algo maior que oprimia tantas mulheres se trata do Estado Irlandês e da Igreja Católica, instituições que dominavam a vida pública e privada da Irlanda do final do século XX. De acordo com Elisa Lima Abrantes:

Para uma geração de mulheres que cresceu em uma atmosfera opressora e de pouca ou nenhuma oportunidade de uma vida autônoma; não havia outra expectativa que não um casamento conveniente e uma vida doméstica de cuidado aos filhos e à família, exclusivamente (2010, p. 167).

O encontro de Breege e Bugler no cemitério foi talvez o ápice de aventura e liberdade que ela vivenciaria, "os dois corpos grudados como um, suas sombras apenas uma, e que parecia apenas um coração latejante querendo sair do peito" (O'BRIEN, 2003, p. 205). Porém, esse encontro representará, ao mesmo tempo, uma realização e um infortúnio para Breege. Tanto que, alguns dias depois, ela procura uma curandeira holandesa conhecida na região:

Eu sonhei. Um pássaro de ouro. Pousou no meu travesseiro e lá ficou, não um pássaro comum. O bico era macio. Despejava gotas em meu ouvido. De manhã se fora. Eu o procurava sob o travesseiro e sob as cobertas, mas se fora. Então uma manhã ele estava morto no travesseiro (O'BRIEN, 2003, p. 224).

A descrição desse sonho e o momento em que O'Brien o insere na narrativa chama atenção para uma apreciação mais detaIhada, para isso, toma-se por base a teoria da interpretação dos 
Dezembros selvagens: pequeno retrato da Irlanda rural e seus conflitos Munike Martins Bonet • Rejane de Souza Ferreira

sonhos de Sigmund Freud (2018). Ela tem por premissa o processo de decifração por meio da análise de frações do conteúdo do sonho mediante o conhecimento de circunstâncias da vida da pessoa em questão, nesse caso, de Breege. Vida de quem o leitor alcança as circunstâncias e detalhes, aspecto importante, pois "o mesmo fragmento de um conteúdo pode ocultar um sentido diferente quando ocorre em pessoas diferentes ou contextos diferentes" (FREUD, 2018, p. 112), mas podemos fazê-lo, pois estamos familiarizados com a história de Breege.

Mediante tais considerações somadas aos conceitos-base de Freud de que "a instigação de um sonho é sempre encontrada nos acontecimentos da véspera" (FREUD, 2018, p. 147), além do sonho ser "uma realização (disfarçada) de um desejo (suprimido ou recalcado)" (FREUD, 2018, p. 159), interpretamos o episódio em que ela visualiza o pássaro morto no travesseiro como alusão ao desejo inconsciente de um aborto. Pois, na manhã anterior, ela havia sentido sinais de gravidez e, em seguida, procura a curandeira. Porém, sem conseguir falar o real motivo de sua visita, ela se despede da mulher, satisfeita com algumas gotas de um remédio para lhe acalmar os nervos, acompanhadas por palavras de encorajamento para que fosse procurar Bugler:

\begin{abstract}
Ela olha para a holandesa, aliviada porque após uma hora de silêncio ela conseguiu falar alguma coisa, em vez de dizer por que está lá. [...] Ela se sente aquecida, aliviada, a mulher lhe dizendo que seus medos não precisam mais ser aprisionados, que, em vez de angústia, em vez de pensamentos ruins e pássaros mortos, ela vai se comover e se lembrar da luz da vela e da pureza da rosa branca (O'BRIEN, 2003, p. 224).
\end{abstract}

O romance se passa na década de 1970 . Contudo, o aborto na Irlanda se tornou descriminalizado apenas em 2018. Logo, a angústia de Breege é uma reação mediante o conhecimento que tinha acerca do tratamento dado a mulheres consideradas "transgressoras" e o destino de seus bebês: 
Dezembros selvagens: pequeno retrato da Irlanda rural e seus conflitos

Munike Martins Bonet • Rejane de Souza Ferreira

Num país onde as mães têm definitivamente um lugar, é evidente que elas [as transgressoras] não têm uma posição na Constituição. Isto é confirmado pelo enorme número de casos denunciados de roubo de crianças às mãos da Igreja e do Estado; milhares de mães, cujos filhos Ihes foram ilegalmente retirados e vendidos pelo Estado, têm sido continuamente impedidas de ter acesso a informações sobre os seus filhos. Aos olhos do Estado, estas mães não existem, uma vez que operaram fora da lei do pai e transgrediram o tabu sexual. O segredo forçado, o sentimento de vergonha, culpa e pecado reforçaram o poder patriarcal inerente ao discurso daquela época ${ }^{4}$ (CLARKE, 2013, p. 3, tradução nossa).

Tantas situações extenuantes psicológica e fisicamente, os delírios de Joseph em busca de sua vingança por meio da disputa de terras, a provável gravidez seguida da desilusão pela indiferença de Bugler, somadas à chegada de sua noiva Rosemary e um inevitável e infeliz encontro entre ambas, provocam em Breege uma espécie de síncope que a faz buscar refúgio na Igreja " - Estou tendo um derrame - sua mente dizia [...]. Alguma coisa terrível acontecera e nada mais havia em seu mundo partido" (O'BRIEN, 2003, p. 240). Porém, e infelizmente, a reação das senhoras que a encontram é uma amostra da incoerência e da percepção que a própria Igreja tinha de mulheres em situações vulneráveis. Essas que encontram Breege criam uma série de suposições, todas com ares de preconceito "perguntaram se ela está bêbada, drogada ou fora de si. [...] - Ela quer chamar atenção. - Insolente é elogio pra ela. - Biruta... Biruta" (O'BRIEN, 2003, p. 243). Por fim, ainda decidem por jogar-lhe água para que se levante:

\footnotetext{
4 Em tradução livre do original: In a country where Mothers quite definitely have a place, they evidently do not have a position in the constitution. This is borne out by the huge number of reported cases of child and identity theft at the hands of the church and state; thousands of mothers whose children were illegally taken from them and sold by the state have been continuously denied access to information regarding their children. In the eyes of the state these mothers do not exist, as they operated outside the law of the father and transgressed the sexual taboo. The forced secrecy, sense of shame, guilt and sin reinforced the patriarchal power inherent in the discourse at that time.
} 
Dezembros selvagens: pequeno retrato da Irlanda rural e seus conflitos Munike Martins Bonet • Rejane de Souza Ferreira

Srta. Noonan, que havia saído depressa, voltou com um jarro de água e com uma determinação que só podia ser chamada de vingança, dá-Ihe um banho, pés, meias, casaco e finalmente o rosto. Estão todos rindo agora, todos rindo de quão grotesca ela está ali, meias molhadas, cabelo molhado, encolhida como um porco-espinho molhado (O'BRIEN, 2003, p. 244).

Após ter encontrado Breege deitada no berço que fica no altar da Igreja, ter descoberto um bilhete no qual ela implorava que Bugler a encontrasse apenas uma vez mais e com a gravidez se tornando evidente, Joseph decide que a solução é interná-la em uma clínica psiquiátrica. Breege demonstrava sintomas de que, mediante o contexto da época, encaminhariam uma mulher à internação: "sensação de asfixia, como se a mulher tivesse uma bola na garganta, [...] tosses e perda de voz; dores em várias partes do corpo; tiques nervosos e espasmos; paralisia, surdez, acessos de choro e desmaios" (SHOWALTER, 2004, p. 33).

O enredo se passa no período em que a Psicanálise vivia seu auge e, de acordo com Elaine Showalter, as epidemias de histeria exigem pelo menos três ingredientes: "médicos e teóricos entusiastas, pacientes vulneráveis e um ambiente cultural favorável" (2004, p. 35). Encontramos esses três elementos no romance: o primeiro parte do Dr. McCann, concluindo o diagnóstico de Breege: "Histeria em último grau" (O'BRIEN, 2003, p. 251); o segundo corresponde à evidente vulnerabilidade de Breege; e o terceiro ao ambiente patriarcal irlandês. Em A história da sexualidade (1988), Michel Foucault escreve que as mulheres foram transformadas em objetos inertes e passivos de um desejo médico de poder. Segundo ele, no fim do século XIX, os corpos femininos foram "tornados histéricos", ou seja, transformados em uma coleção de sintomas físicos e psicológicos pela profissão médica. Assim, observamos que os sintomas de Breege sinalizavam uma crise nervosa, porém jamais deveriam servir de justificativa para a internação em uma clínica psiquiátrica. 
Dezembros selvagens: pequeno retrato da Irlanda rural e seus conflitos

As contestações e teorizações feitas a partir da teoria freudiana acerca da histeria não produziram ainda um consenso, contudo, compreendeu-se, a partir de então, que a histeria havia sido dissociada da experiência cotidiana e "em vez de explicar a histeria como mais um ponto no espectro universal do comportamento humano, os psicanalistas a fizeram parecer aberrante e enigmática" (SHOWALTER, 2004, p. 68). Ou seja, todos podem apresentar episódios psicossomáticos ocasionais, assim como o que Breege vivenciou, uma crise de afonia histérica, desencadeada pela somatização de situações asfixiantes, e não um estado patológico que justificasse uma reação tão violenta, reação esta que atesta a força do fator cultural como vetor de atuações fortemente punitivas e restritivas para as mulheres. Joseph estava mais preocupado em afastar sua irmã de Bugler do que em cuidar de sua saúde mental, "McCann e ele [Joseph] disseram que isso era paixonite de criança dentro de uma mulher de vinte e dois anos, uma loucura" (O'BRIEN, 2003, p. 248).

Em relação aos silêncios de Breege, isto é, a incapacidade comunicativa que ela enfrenta em todos os momentos em que tenta externar o que sente, podemos interpretar, com base em Showalter, que se originaram a partir do sofrimento que ela tinha por não conseguir se expressar. Segundo essa crítica literária feminista, no século XIX, as mulheres diagnosticadas com histeria "sofriam da falta de uma voz pública para articular a opressão econômica e sexual, e os sintomas - mutismo, paralisia, desmaios - pareciam metáforas corporais para o silêncio, a imobilidade e a hiperfeminilidade impostos a elas pela sociedade" (2004, p. 81).

O problema dessas limitações na comunicação feminina não se refere a uma insuficiência linguística das mulheres, mas a uma negação cultural da totalidade dos recursos da língua, forçando-as aos silêncios e aos eufemismos (SHOWALTER, 1994). Breege cresceu sufocada em meio a um ambiente familiar dominador e uma atmosfera cultural opressora. Quando conhece Bugler, ela projeta nele a realização do ideal de amor romântico e uma possibilidade de viver de outra forma. Contudo, a relação patológica que 
Dezembros selvagens: pequeno retrato da Irlanda rural e seus conflitos Munike Martins Bonet • Rejane de Souza Ferreira

o irmão estabeleceu para com ela e sua impotência diante disso Ihe obstruiriam de todas as formas. Joseph, não satisfeito por tê-la enclausurado, ainda procurou por Bugler e o assassinou após ouvi-lo admitir o envolvimento que tivera com sua irmã e a intenção de romper com a noiva Rosemary para assumir Breege. A atitude final de Joseph condenou sua irmã a ficar para sempre na situação inicial de sua esposa substituta com o agravante de que agora seu suposto marido ainda estava preso por assassinato.

O'Brien não fecha o enredo. Segundo Abrantes (2010), "os finais abertos, próprios das narrativas modernistas e pós modernistas, também são frequentes em Edna O’Brien. Não há resolução em seus enredos, mas o caráter cíclico e descontínuo da história está presente tanto na forma quanto no conteúdo" (p. 196). Assim, ilustra-se a descontinuidade ao final de Dezembros Selvagens:

Rosemary está lá em cima. Breege sabe pelas luzes nas janelas cada noite e às vezes ela olha para cima na direção dela e se pergunta se as antigas guerras continuam fermentando de novo, e se elas, mulheres, serão chamadas a lutar a luta insaciável em nome da honra e da terra e da família e do sangue [...] segurando o ventre ela volta, volta no tempo àquelas forças sem nome e espectrais de que ela é feita, na esperança que haja comunhão entre os vivos e os mortos, entre aqueles que estão do lado da vida e anunciam o amor (O"BRIEN, 2003, p. 304).

O final do romance expressa, através de Breege, o desejo de um movimento feminista em busca de emancipação. Ela sobrevive e permanece carregando em seu ventre o filho que simboliza uma hibridização que subverte as percepções que limitam a definição de irlandês, de modo que, ao final do livro, O'Brien sugere um ambiente a ser construído por mulheres que, mesmo subjugadas, estão em busca de construir suas subjetividades em meio aos conflitos sociais e culturais nos quais estão inseridas, como uma mensagem de contestação e de busca pelo autodesenvolvimento. 
Dezembros selvagens: pequeno retrato da Irlanda rural e seus conflitos Munike Martins Bonet • Rejane de Souza Ferreira

\section{Conclusão}

Por meio do enredo da obra O'Brien, não só se questiona a percepção hegemônica de identidade cultural, como também problematiza as fronteiras entre a terra e a mulher. Porquanto, o tratamento dado à terra se estende à forma como as próprias muIheres são tratadas. O sentimento de posse se mistura de forma tão intrincada que Joseph viu o envolvimento de Breege com o exilado como uma dupla traição, ela estaria traindo-o e igualmente traindo a Irlanda ao "misturar" seu sangue ao de um homem "não irlandês", pois Bugler nega o Irishness. O exilado havia cruzado as fronteiras da terra e da tradição e violado os códigos sociais invisivelmente estabelecidos pelo Estado patriarcal e pela construção identitária das comunidades locais.

A temática levantada buscou ainda expor as consequências dessas percepções aqui retratadas, especialmente por meio do personagem Joseph, que afetaram diretamente sua irmã. Por isso, tomamos por base teóricos que se ocuparam de analisar a questão dos silenciamentos femininos e igualmente das patologias associadas à formação identitária masculina e sua relação com o meio.

Tendo chegado ao final deste pequeno retrato, esperamos ter sido possível demonstrar o quanto aspectos e percepções culturais limitantes e intransigentes são catalizadoras de conflitos que afetam a vida cotidiana e podem causar danos a figuras sociais mais vulneráveis, como é o caso das mulheres. Por fim, esse diálogo entre literatura e tradição cultural se faz parte essencial do processo de desconstrução de estereótipos e da problematização de conflitos que, até então, permaneciam camuflados por uma suposta aparência de felicidade pautada em princípios e valores. 
Dezembros selvagens: pequeno retrato da Irlanda rural e seus conflitos Munike Martins Bonet • Rejane de Souza Ferreira

\section{Referências}

ABRANTES, E. L. O Passado que não Passa: memória, história e exílio na ficção de Edna O'Brien. 2010. 243 f. Tese (Doutorado em Literatura Comparada) - Instituto de Letras, Universidade Federal Fluminense Niterói, 2010.

CLARKE, L. Mother Ireland... The Myth. 2013. Disponível em: <https:// nls.org/wp content/uploads/Pdf/Mother\%20Ireland\%20\%e2\%80\%a6The\%20Myth.pdf>. Acesso em: 25, maio 2020.

FERREIRA, R. S. Voz e Consciência Narrativa: a percepção familiar através da perspectiva Feminina em três romances Irlandeses. 2014. n.p. Tese (Doutorado em Letras e Linguística) - Universidade Federal de Goiás - Goiânia, 2014.

FOUCAULT, M. História da sexualidade I: a vontade de saber. Trad. de Maria Thereza da Costa Albuquerque e J. A. Guilhon Albuquerque. Rio de Janeiro: Edições Graal, 1988.

FREUD, S. Totem e Tabu. In: FREUD, S. Totem e Tabu. Edição Standard Brasileira das Obras Completas de Freud, v. 13. Rio de Janeiro: Imago, 1990, p. 11-125.

FREUD, S. Totem e Tabu. A interpretação dos sonhos. Trad. de Walderedo Ismael de Oliveira. [20. ed.]. Rio de Janeiro: Nova Fronteira, 2018.

HALL, S. et al. Identidade e Diferença: a perspectiva dos estudos culturais. 15 ed., Petrópolis, RJ: Vozes, 2014.

LACAN, J. Sobre o complexo de Castração (cap. XIII). In: LACAN, J. 0 seminário 4: a relação de objeto. Texto estabelecido por Jacques-Alain Miller; Trad. de Dulce Duque Estrada. Rio de Janeiro: Jorge Zahar Ed., 1995. p. 220-236.

NOCCHI, R. F. A estrutura do complexo de Édipo em Freud e Lacan. 2019. 37 f. Trabalho de Conclusão de Curso (Bacharelado em Psicologia) - Universidade Regional do Noroeste do Estado do Rio Grande do Sul ljuí, 2019. 
Dezembros selvagens: pequeno retrato da Irlanda rural e seus conflitos Munike Martins Bonet • Rejane de Souza Ferreira

O'BRIEN, E. Dezembros selvagens. Trad. de Cyana Leahy. Rio de Janeiro: Bertrand Brasil, 2003.

RIBEIRO, G. M. O novo testamento, fone primária das experiências das primeiras comunidades cristãs. Disponível em: <http://www. dhi.uem.br/gtreligiao/pdf/st5/Ribeiro,\%20Gilvaldo\%20Mendes.pdf >. Acesso em: 24, abr. 2020.

SHOWALTER, E. Histórias Histéricas: a histeria e a mídia moderna. Trad. de Heliete Vaitsman. Rio de Janeiro: Rocco, 2004.

SHOWALTER, E. A crítica feminista no território selvagem. In: Hollanda, Helena Buarque de. (Org). Tendências e impasses: o feminismo como crítica da cultura. Rio de Janeiro: Rocco, 1994. p. 23 - 58.

SLIVKA, J. A. Irishness and Exile in Edna O'Brien's "Wild Decembers" and "In the Forest". New Hibernia Review / Iris Éireannach Nua, v. 17, n. 1, p. 115-131, 2013. Disponível em: <www.jstor.org/stable/24625079. Acesso em 27.03.2020>. Acesso em: 20, fev. 2020.

SOUSA, A. P. A mimese da relação triádica entre identidade, cultura e poder em três contos de Edna O’Brien. 2020. 95 f. Dissertação (Mestrado em Literatura) - Universidade Federal do Tocantins Tocantins, 2020. 